\title{
A Preliminary Usability Evaluation of Hemo@Care: A Web-Based Application for Managing Clinical Information in Hemophilia Care
}

\author{
Vasco Saavedra $^{1}$, Leonor Teixeira $^{1,2}$, Carlos Ferreira ${ }^{1,3}$, and Beatriz Sousa Santos ${ }^{4,5}$ \\ ${ }^{1}$ Department of Economics, Management and Industrial Engineering, \\ University of Aveiro Portugal \\ ${ }^{2}$ Governance, Competitiveness and Public Politics (GOVCOPP), \\ University of Aveiro Portugal \\ ${ }^{3}$ Operational Research Centre (CIO), \\ University of Lisbon Portugal \\ ${ }^{4}$ Department of Electronics, Telecommunications and Informatics, \\ University of Aveiro Portugal \\ ${ }^{5}$ Institute of Electronics and Telematics Engineering of Aveiro (IEETA) \\ Portugal \\ \{vsaavedra, lteixeira, carlosf, bss@ua.pt\}@ua.pt
}

\begin{abstract}
In this work, an overall description of the methods used and the results obtained in the on-going evaluation of hemo@care is presented. To help understanding the methods and results, we first give an overview of the main functionalities of hemo@care, which is a web application to manage the clinical information in hemophilia care, developed to be used by hematologists, nursing staff and patients suffering from hemophilia. Following we described the methods used in this particular evaluation, and finally we present the main results and general conclusions of these preliminary usability evaluation.
\end{abstract}

Keywords: Health information system,Hemo@care, Usability evaluation.

\section{Introduction}

The main objective of usability testing is to identify usability deficiencies and, at the same time, to create functional products that are easy to use [1]. We considered these ideas when evaluating our application, adapting usability testing techniques to obtain feedback from users while they performed a set of tasks in a health information system (HIS), called hemo@care, currently under development.Hemo@care is a web application to manage the clinical information in hemophilia care, developed to be used by hematologists, nursing staff and patients suffering from hemophilia. It incorporates a extensive dataset including medical information: medical history, physical examination results, laboratory data, detailed information on the primary diagnosis, symptoms and manifestations, treatments, potential complications, etc., and non-medical information: demographic information, socio-psychological background, etc. In a nutshell, it provides healthcare professionals (HCP) the tools to manage all the essential information regarding patients' data and treatments. Patients are deeply involved in this process too, 
as the system also provides the tools for managing their individual treatments, delegating to them the responsibility for data accuracy.

During the development process of this complex web application we used a human-centered design approach within an iterative process, which started by recognizing the potential users, their contexts of use and the tasks they need to perform $[2,3]$. After this, the design continued by using formative evaluation along different phases of the development cycle of hemo@care with strong end-user participation [4]. Moreover, several well-known usability methods, as heuristic evaluation, observation, questionnaires and interviews, were used in the latter phases of the process: basically we used heuristic evaluation followed by testing with users in a formal evaluation and finishing with informal evaluation, conducting to design revision.

In this paper we present the results of this preliminary usability evaluation and describe their impact in a revision version of hemo@care. To help understanding the methods and results presented, we first give an overview of the hemo@care, as well as the main modules and functionalities; then we describe the evaluation methods and methodology applied and the main results obtained, and finally we present conclusions and future work.

\section{Overview of Hemo@care}

The hemo@care web application was designed to provide a tool to respond a specific problem regarding management information process in a Hemophilia Treatment Center (HTC). The existence of parallel data creation processes (as home treatment records by patients) followed by the inexistence of secure storing and data forwarding mechanisms to the HTCs is one of these problems. Part of the hemophilia treatments are made in the patient's homes and these treatments data have to be correctly stored and forward to the HTC for patient's data control. Traditionally, patients annotate this data in specific paper datasheets and send them to HTC by traditional mail, fax or deliver in person. On one hand, due to the lack of security of this process, there is a strong possibility of resulting in redundant or incorrect data. On the other hand, the lack of knowledge of this data by the clinical staff may adversely affect clinical decisions concerning the patient's treatment.

Moreover, the lack of automatic stock management of treatment products (Coagulation Factor Concentrate (CFC)) was also another motivation to develop the present tool. The CFC is extremely expensive and to minimize potential waste, patients are advised to control the expiration date of their personal stock, returning to their HTC all products which expiration date is approaching. In fact this process is very hard accomplished without automatic mechanisms.

Aiming to respond to these specific needs, we developed a web application solution (hemo@care) that aggregates three different modules: Patient Clinical Data Management (PCDM), Treatment Data Management (TDM) and CFC Stock Data Management (CFCSDM).

- Patient Clinical Data Management (PCDM) Module - This module manages the patient's clinical data. Although parts of this data are available from other Information Systems (IS), it is very difficult to obtain aggregated reports to support clinical treatment analysis. Moreover, there is a large number of data related to the 
specifications of the hemophilia pathology that are not supported by other ISs, and are stored in paper files or in isolated ISs. This module (PCDM) aims to provide physicians with the tools to manage the patient's clinical data, also providing the means to transform the flat information records stored in other ISs in relevant information which can be aggregated in several different views.

- Treatment Data Management (TDM) Module - This module is responsible for the management of the patient treatment information lifecycle, which data is generated in the scope of CFC treatments. There are three actors that interact with this module: the nurse, the patient and the physician, Fig.1.

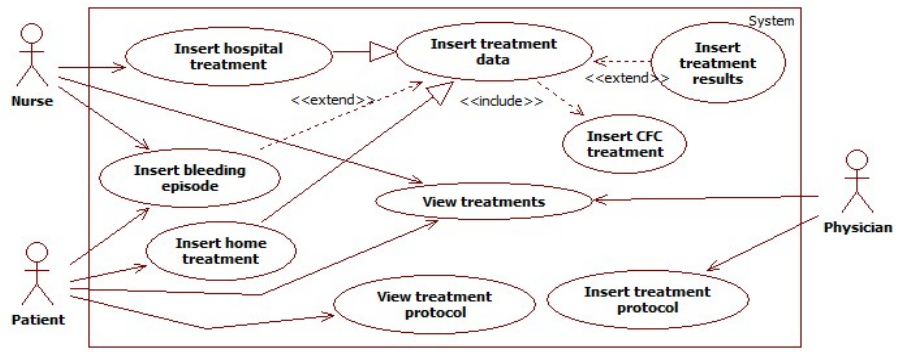

Fig. 1. Generic use case diagram of the TDM module

The nurse and the patient are responsible by inserting treatments result data, respectively, in a hospital and homemade regime, including the bleeding episode associated and the CFC administrated in the scope of that treatment. The physician controls the treatment evaluation process, consulting the related information and is responsible for the insertion of the specific treatment protocol.

- CFC Stocks Data Management (CFCSDM) Module - In a nutshell, this module provides the tools for managing the stocks of the products used in the hemophilia treatment, specifically the CFC. This module is integrated with the TDM, providing an automatic management of CFC products. Two actors interact with this module: the nurse and the patient, Fig.2.

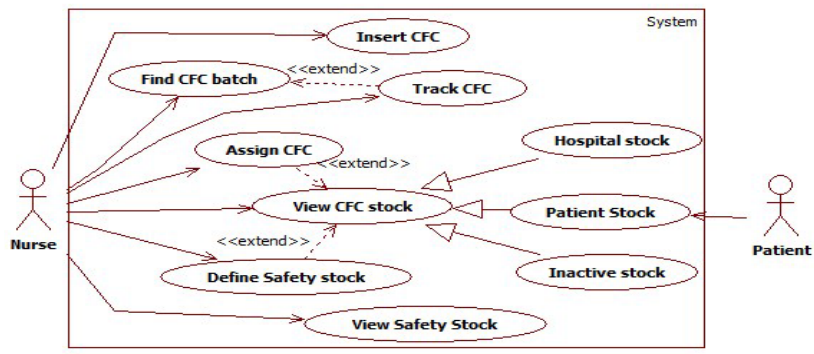

Fig. 2. Generic use case diagram of the CFCSDM module 
These three different modules (meant to be used by physician, nurses and patients) were evaluated in the latter phases of the development process using different approaches. While, the physician and nurse components were evaluated in the field with a small group of actual end-users (hematologists and nurses) through observation and interviews, the user interface corresponding to the patient and nurse component was evaluated in the laboratory using various methods.

\section{Study Protocol and Evaluation Methods}

The aim of this study was to identify potential usability problems in the TDM and CFCSDM modules of the hemo@care system and gather qualitative information to propose guidelines for correcting and redesigning the identified processes and interfaces. In order to detect usability problems and assess the user interface learnability [5-8], this evaluation was performed by Human-Computer Interaction (HCI) students in a process divided in three different collaborative phases, Fig.3.

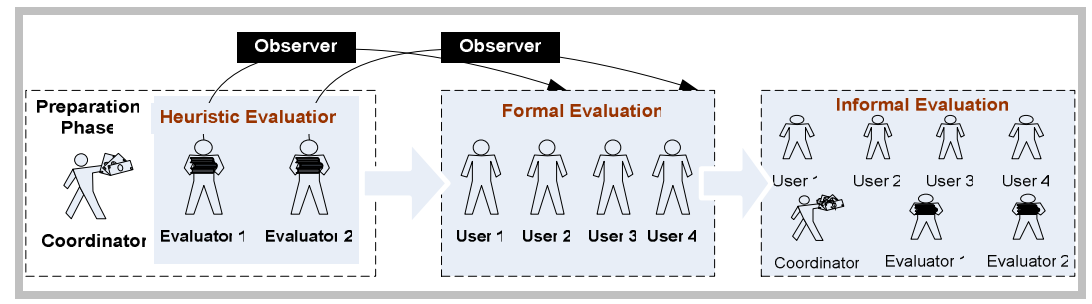

Fig. 3. Evaluation process and participants involved

- The preparation phase involved a coordinator (research collaborator) and two students. Firstly the students acquired a general understanding of the application and next they inspected the system evaluating it based on heuristic evaluation [9]. Each identified usability problem was recorded in a written report, including the problem description, a clear explanation of why it doesn't conform to the usability principals, and a severity rate.

- The second phase of the evaluation (formal evaluation) involved a small number of students with HCI knowledge but without problem domain knowledge. At the beginning of the evaluation session, the coordinator briefly summarised the application functionalities. This was followed by fifteen minutes of system testing by the users. We decide to profit from the knowledge acquired by the students involved in the previous phase, and asked them to act as observers in this phase. Four students were chosen given their HCI background, simulating end-user roles. The latter students had to perform a set of predefined tasks derived from use case diagram, while the two observers would register times, task completeness, etc., as well as assisting them if needed. The aim of this process was to assess the user interface learnability and also to understand how usage could be improved. After all students completed the tasks, a specific questionnaire was presented. This questionnaire was prepared to collect basic demographic data, and a group of questions to assess user reactions and general opinion about the system. 
- The last phase of the evaluation involved all six participants (4 users and 2 observers) as well as the coordinator. The main purpose of this phase was to have an informal conversation where students would give their opinions and suggestions on how to improve system usability.

We chose students of HCI course due to their knowledge about usability evaluation that made them reasonably suitable as subjects for the evaluation the user interfaces.

\subsection{Tasks in the Formal Evaluation}

In the formal evaluation, the tasks to be carried by the users were chosen to represent the most common activities in hemo@care system performed by nurse and patient actors. We defined 15 tasks for the users to perform during the observation session. These tasks refer to the components of the treatment data management (TDM) and CFC stock data management (CFCSDM) modules, which will have to be performed by patients and nurses and are described in use case diagrams presented in section 2 .

Table 1. Use case and tasks mapping

\begin{tabular}{|c|c|c|c|c|}
\hline & Actor & Use Case & Task \# & Task Specification \\
\hline \multirow{9}{*}{ 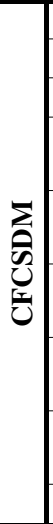 } & Nurse & Insert CFC & 1 & Insert an order of CFC products in the system \\
\hline & Nurse & Define Safety Stock & 2 & Define the safety stock of a specific product \\
\hline & Nurse & View CFC Stock & 3 & View the details of a specific CFC product \\
\hline & Nurse & View Safety Stock & 4 & $\begin{array}{l}\text { View all the products which stock level is } \\
\text { bellow the safety stock }\end{array}$ \\
\hline & Nurse & Track CFC & 5 & $\begin{array}{l}\text { View the tracking details of a specific CFC } \\
\text { batch }\end{array}$ \\
\hline & Nurse & Track CFC & 6 & $\begin{array}{l}\text { Analyze the tracking details to know in which } \\
\text { patients the product was used }\end{array}$ \\
\hline & Nurse & Track CFC & 7 & $\begin{array}{l}\text { Analyze the tracking details to know in which } \\
\text { treatments the product was used }\end{array}$ \\
\hline & Nurse & View Patient Stock & 10 & $\begin{array}{l}\text { View all the patients with CFC products in } \\
\text { home }\end{array}$ \\
\hline & Nurse & Assign CFC & 11 & Assign two CFC products to a specific patient \\
\hline \multirow{6}{*}{ 主 } & $\begin{array}{l}\text { Patient } \\
\text { Nurse }\end{array}$ & View Treatments & 8 & View the details of a specific treatment \\
\hline & Patient & $\begin{array}{l}\text { Insert home } \\
\text { treatment }\end{array}$ & 9 & $\begin{array}{l}\text { Insert a post operation treatment with specific } \\
\text { orthopedic equipment }\end{array}$ \\
\hline & $\begin{array}{l}\text { Patient } \\
\text { Nurse }\end{array}$ & View Treatments & 12 & List all treatments that meet a specific criteria \\
\hline & Nurse & View Treatments & 13 & $\begin{array}{l}\text { Verify the batch number used in a specific } \\
\text { patient in the scope of a specific treatment. }\end{array}$ \\
\hline & Nurse & $\begin{array}{l}\text { Insert hospital } \\
\text { treatment }\end{array}$ & 14 & $\begin{array}{l}\text { Insert the details of a hospital treatment given } \\
\text { to a specific patient. }\end{array}$ \\
\hline & Nurse & $\begin{array}{l}\text { Insert CFC } \\
\text { Treatment }\end{array}$ & 15 & $\begin{array}{l}\text { Insert the CFC products used in the scope of } \\
\text { the task number } 14 .\end{array}$ \\
\hline
\end{tabular}


Table 1 presents a brief summary of the task performed by users that participated in this evaluation, the corresponding use case and involved actors.

Each task had to be completed in a given time window, defined regarding the user's profile and the perceived reasonable time for the execution of the task. These tasks were monitored by an observer and, throughout the evaluation session. For each task the observer had to register the some data concerning user performance: the time spent performing the task; if the user finished the task; if the user asked for help to perform the task; if the user had made a mistake; the difficulty level perceived by the observer in the user while executing the task and any additional observation considered relevant. Regarding the difficulty level, users' and the observers' answers were measured using a four level scale, level one being the least favorable (very difficult) and level four the most favorable answer (very easy).

\subsection{Questionnaire}

After performing all tasks, users were invited to answer a brief questionnaire, giving their global opinion about the hemo@care system. Beyond demographic data, the questionnaire included a large number of questions regarding the system being evaluated. These questions were aimed to know the users opinion regarding the system use (easiness of use, content consistency, adequate and perceivable functionalities, etc.) and specific aspects of the system (layout, easiness of navigation, clear and appropriated error and information messages, etc.). The questionnaire was elaborated having as base the QUIS (Questionnaire for User Interaction Satisfaction) developed in the University of Maryland [10].

\section{Results and Discussion}

We had the collaboration of six (masculine gender) students. The median age of this group was 22 years. Two of these students were trained for the observer role and to perform a heuristic evaluation, and four of them performed the predefined tasks. The results of users' reactions to hemo@care are presented in Table 2.

Table 2. Users opinion on general and specific aspects of hemo@care in a scale with five levels ( 1 - complete disagreement; 5 - complete agreement)

\begin{tabular}{lcccc}
\hline \multicolumn{1}{c}{ Feature } & U1 & U2 & U3 & U4 \\
\hline 1 - It is easy to find the information & 1 & 2 & 3 & 2 \\
\hline 2 - The terminology used is consistent & 4 & 5 & 5 & 4 \\
\hline 3 - Help is needed to perform some tasks & 2 & 3 & 3 & 2 \\
\hline 4 -The characters (text) are easy to read & 4 & 4 & 4 & 5 \\
\hline 5-The information layout is adequate & 3 & 3 & 5 & 4 \\
\hline 6-The icons used are intuitive & 4 & 3 & 4 & 4 \\
\hline 7 -The interface is visually appealing & 4 & 4 & 4 & 4 \\
\hline 8-The system is pleasant to use & 5 & 5 & 5 & 4 \\
\hline
\end{tabular}

These results convey a positive reaction to the application; except for feature 1 (It is easy to find information) and maybe the feature 3 (Help is needed to perform some tasks). 
As a result of the heuristic evaluation, several minor problems were detected. Table 3 presents a brief summary of these problems, the corresponding heuristic and a suggestion to correct the problem and/or an observation.

Table 3. General problems, heuristic and action considered

\begin{tabular}{|c|c|c|}
\hline Problem & Heuristic & Action / Observation \\
\hline $\begin{array}{l}\text { Due to the extremely } \\
\text { technical nature of the } \\
\text { medical terms, several } \\
\text { words and concepts were } \\
\text { unfamiliar to the user }\end{array}$ & $\begin{array}{l}\text { Match between } \\
\text { system and the } \\
\text { real world }\end{array}$ & $\begin{array}{l}\text { All the words/descriptions used in the } \\
\text { system were stored in specific properties } \\
\text { file that was developed with the help of the } \\
\text { domain experts (i.e., healthcare profession- } \\
\text { als). }\end{array}$ \\
\hline $\begin{array}{l}\text { Several errors were } \\
\text { reported when submitting } \\
\text { the data }\end{array}$ & $\begin{array}{c}\text { Error } \\
\text { prevention }\end{array}$ & $\begin{array}{l}\text { All the errors reported were due to a } \\
\text { prototype limitation. The system will have } \\
\text { two types of error prevention mechanisms: } \\
\text { client and server side. The evaluated } \\
\text { prototype only had server side validation } \\
\text { implemented. }\end{array}$ \\
\hline $\begin{array}{l}\text { When an error occurred, } \\
\text { technical data (error code } \\
\text { and description) were } \\
\text { displayed. }\end{array}$ & $\begin{array}{l}\text { Help users } \\
\text { recognize, } \\
\text { diagnose, and } \\
\text { recover from } \\
\quad \text { errors }\end{array}$ & $\begin{array}{l}\text { This was due to a prototype limitation. On } \\
\text { an error occurrence, the system will display } \\
\text { non technical and informative information, } \\
\text { automatically logging the technical infor- } \\
\text { mation for further analysis. }\end{array}$ \\
\hline $\begin{array}{l}\text { Although the system } \\
\text { displayed an help icon, it } \\
\text { doesn't have any } \\
\text { functionality }\end{array}$ & $\begin{array}{c}\text { Help and } \\
\text { documentation }\end{array}$ & Not implemented in the prototype. \\
\hline
\end{tabular}

The data collected from tasks observation, revealed minor difficulties in performing some tasks, namely tasks 9, 11 and 15 (Table 1) that presented, in general, a high time of execution. These tasks are concerned with 'insert treatments (9)', 'assign CFC product (11)' and 'insert CFC treatment (15)'. Analyzing the tasks and considering users' comments in the final discussion (informal session), we concluded that for some tasks, the specific operation flow was not the most correct. This aspect was also confirmed by the answers to the questionnaire concerning feature 1 (It is easy to find information) and feature 3 (Help is needed to perform some tasks).

Based on the qualitative analysis of the data obtained through different evaluation components of this study, the operations' flow complexity was maybe the most relevant usability problem identified during this preliminary evaluation. To improve it, those flows were reformulated, leading to simpler and easy to use interfaces. In order to demonstrate how this redesign was performed, we present the modifications performed on task 11 - "assign CFC". Fig.4 presents the corresponding operation flow for task 11, before and after reformulation.

As a result of this reformulation, task forms were redesigned too. Fig.5 and Fig.6 present the corresponding forms for task 11, before and after reformulation. 


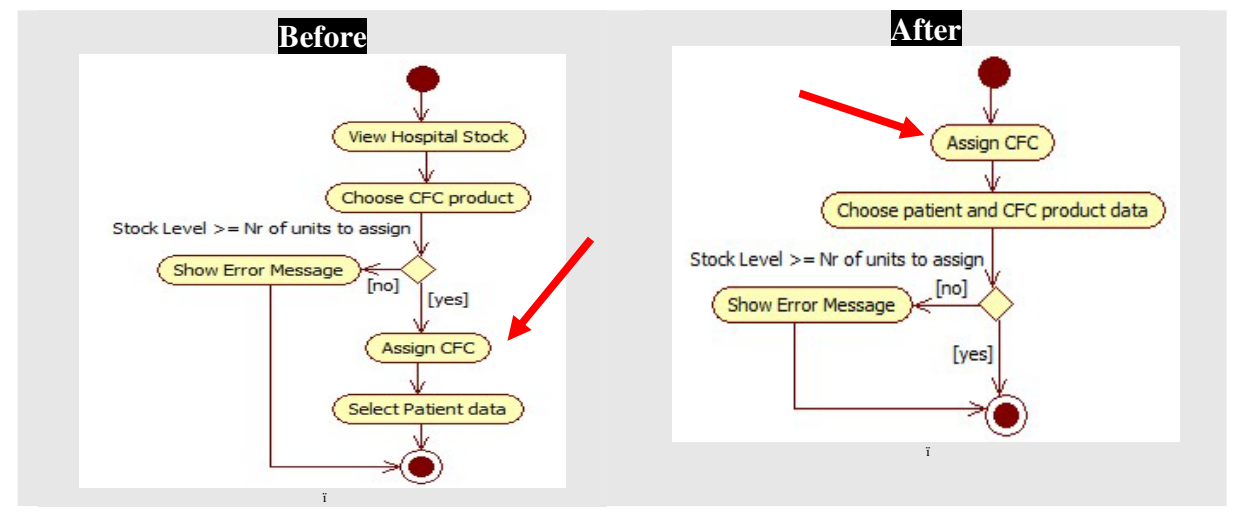

Fig. 4. Example of operations' flow for task 11 before and after reformulation

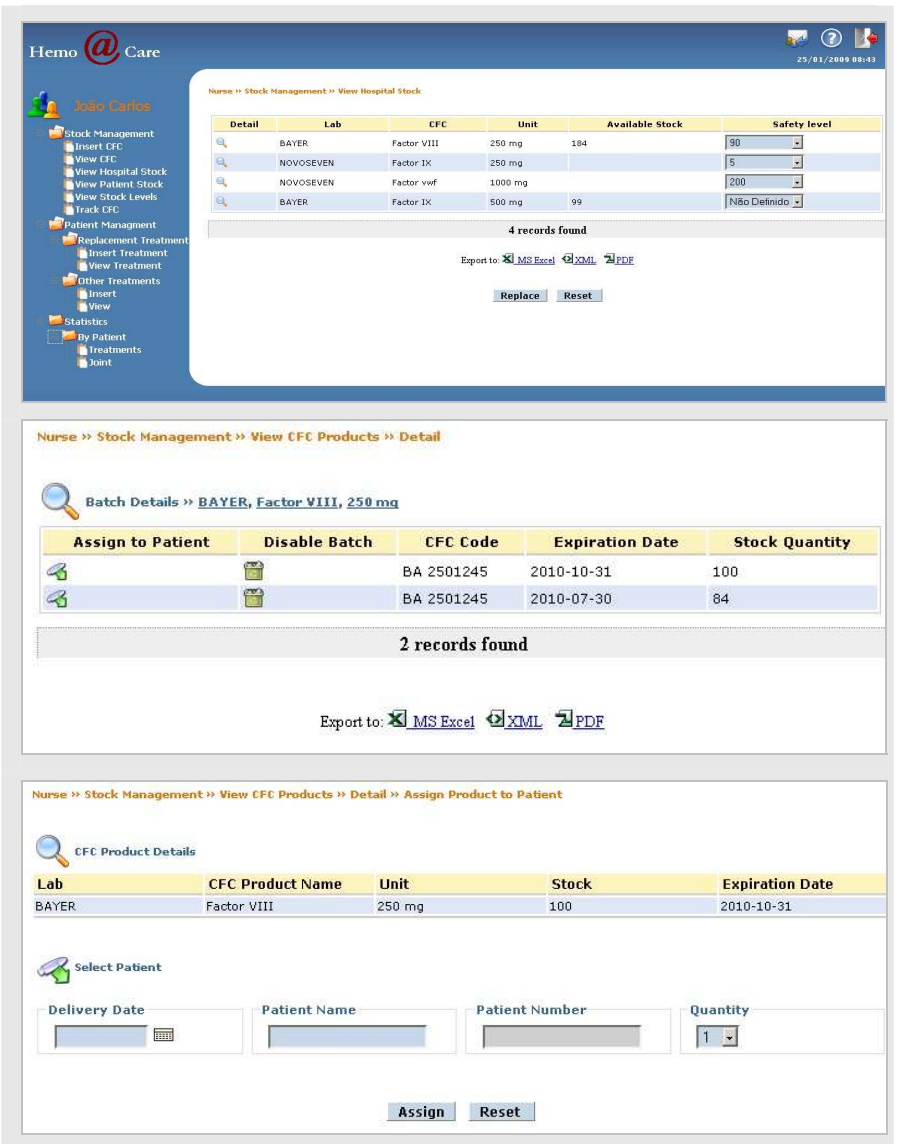

Operation 1 - The user selects "view hospital stock" in the left menu. The system presents the next form where the user performs operation 2;

Operation 2 - The user views all the available CFC and, based on this information, selects the product and clicks in "assign to patient". The system presents the next form where the user performs operation 3;

Operation 3 - The user introduces the patient name (patient number is automatically filled) as well as the amount of CFC delivered to the patient.

Fig. 5. Form sequence to perform task "assign CFC" before reformulation 
We concluded that we could achieve the same result by aggregating all the previous information in a single interface, in accordance with of operations' flow represented in the Fig.4.

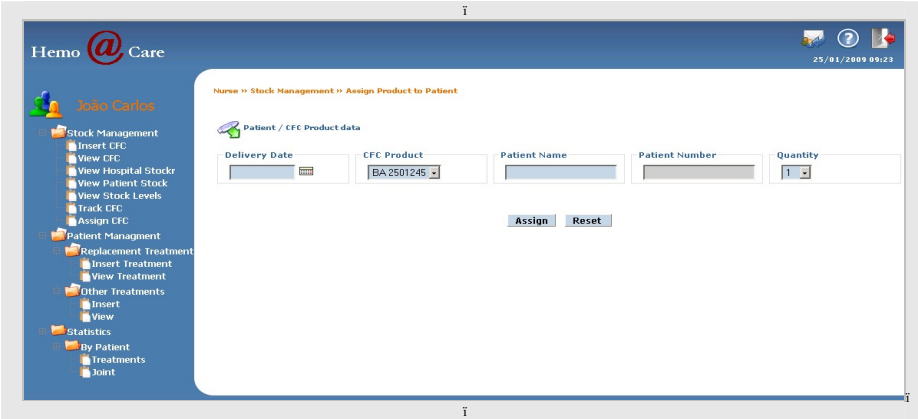

The user can selects directly the task "assign CFC". The three operations presented before are now aggregated in one single operation, Fig. 6.

Fig. 6. Single form to perform the task "Assign CFC" after reformulation

\section{Conclusion}

In this paper we describe the on-going evaluation of a health information system (HIS), called hemo@care, currently under development.Hemo@care is a web application to manage the clinical information in hemophilia care, developed to be used by hematologists, nursing staff and patients suffering from hemophilia. During the development process of this HIS we used different techniques and methods illustrating the results and evaluating the design along different phases of the iterative development cycle. The requirements were constantly refined and new requirements were identified. Usually in this type of approach, usability studies start early in the design process, with techniques of formative evaluation, and continue along the development cycle until the end of product development through summative evaluation. In the latter phases of the process we applied several usability evaluation methods (heuristic evaluation, task observation and questionnaire) in order to find usability problems and elicit new ideas that will, eventually, allow us to improve the usability of the system. This latter was the main subject of this work, where we presented the design and results of the preliminary user evaluation and also briefly described the implication of these results in a new version of the hemo@care system.

The evaluation results of the data collected from tasks observation revealed minor difficulties in performing some tasks having this aspect also been confirmed by the answers to the questionnaire. Based on the qualitative analysis of the data obtained through different evaluation components including the final informal conversation, the operations' flow complexity was, in fact, the most relevant usability problem identified during this preliminary evaluation.

The questionnaire gave us a general positive idea about the usability of the hemo@care system, except in the 'ease of use' dimension.

These results contributed to increment some improvement in new version of hemo@care system, namely in the operation flow and tasks. In general form, we are pleased with results obtained; still, we intend to evaluate the new version of hemo@care system with a large group of users. 


\section{Acknowledgements}

The authors wish to thank all students of the Human-Computer Interaction course, of the University of Aveiro, that have graciously collaborated, emphasizing the precious help of the Hugo Félix and José Pinto in this work.

\section{References}

1. Rubin, J.: Handbook of usability testing: how to plan, design, and conduct effective tests. John Wiley, New York (1994)

2. Teixeira, L., Ferreira, C., Santos, B.S.: Web-enabled System Design for Managing Clinical Information. In: Wickramasinghe, N., Geisler, E. (eds.) Encyclopedia of Healthcare Information Systems. Medical Information Science Reference, vol. III, pp. 1398-1406. IDEA Group Inc., Hershey (2008)

3. Teixeira, L., Ferreira, C., Santos, B.S., Martins, N.: Modeling a Web-based Information System for Managing Clinical Information in Hemophilia Care. In: Proceedings of 28th Annual International Conference of the IEEE Engineering in Medicine and Biology Society (EMBS), pp. 2610-2613. IEEE CNF, NY (2006)

4. Teixeira, L., Ferreira, C., Santos, B.S.: Using Task Analysis to Improve the Requirements Elicitation in Health Information System. In: Proceedings of 29th Annual International Conference of the IEEE Engineering in Medicine and Biology Society (EMBS), pp. 36693672. IEEE CNF, Lyon (2007)

5. Dix, A., Finley, J., Abowd, G., Russell, B.: Human Computer Interaction. Pearson Education, Harlow (2004)

6. Mitchell, P.: A Step-by-step Guide to Usability Testing. iUniverse (2007)

7. Peute, L.W.P., Jaspers, M.W.M.: The significance of a usability evaluation of an emerging laboratory order entry system. International Journal of Medical Informatics 76, 157-168 (2007)

8. Preece, J., Rogers, Y., Sharp, H., Benyon, D., Holland, S., Carey, T.: Human Computer Interaction. Addison-Wesley, UK (1994)

9. Nielsen, J.: Ten Usability Heuristics (2005),

http: //www.useit.com/papers/heuristic/heuristic_list.html (visited on 21/02/2009)

10. Shneiderman, B.: Designing the User Interface - Strategies for effective Human-Computer Interaction. Addison-Wesley, Reading (1998) 